\section{Gastric fundal varices with an exposed microcoil after the combined BRTO and PTO therapy}

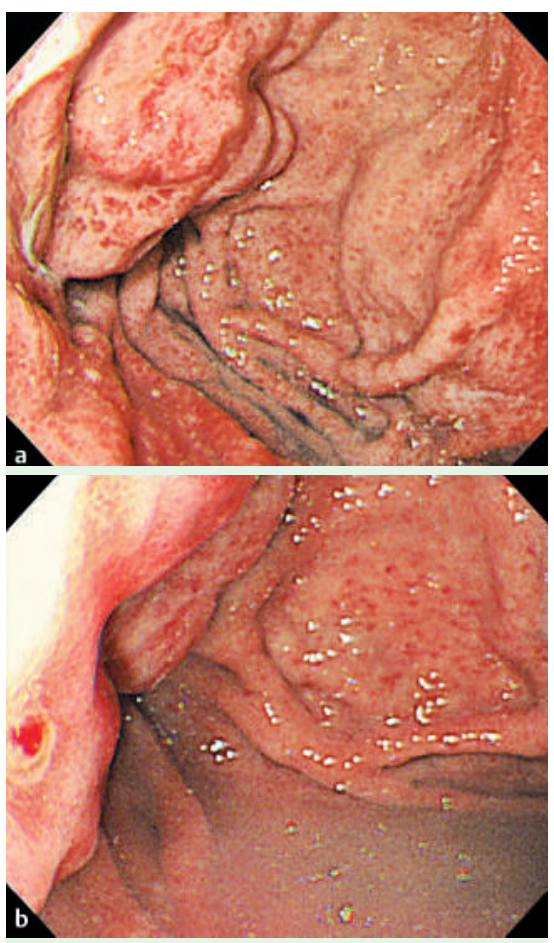

Fig. 1 Emergency upper endoscopic examination revealed a gastric fundal varices and b a red spot in the erosion at the top of the varices.

A 74-year-old man was admitted to our hospital with tarry stool as his chief complaint. He had been suffering from liver cirrhosis (type $\mathrm{C}$ ) and had a clinical history of receiving treatment for hepatocellular carcinoma. Emergency upper endoscopic examination revealed gastric fundal varices with an erosion, in which a red spot was observed ( Fig. 1) [1]. There were no other lesions which would result in tarry stool, including the esophageal varices. We therefore concluded that this red spot had caused gastric variceal hemorrhage. We performed a combined balloon-occluded retrograde transvenous obliteration (BRTO) procedure and percutaneous transhepatic obliteration (PTO) [2]. Percutaneous transhepatic portographic images showed that the afferent vein of the gastric varices consisted mainly of the posterior gastric vein ( Fig. 2 a) and short gastric vein ( $\bullet$ Fig. 2 b), and that the efferent vein was the gastrorenal shunt [3]. Some microcoils were placed in the short gas-

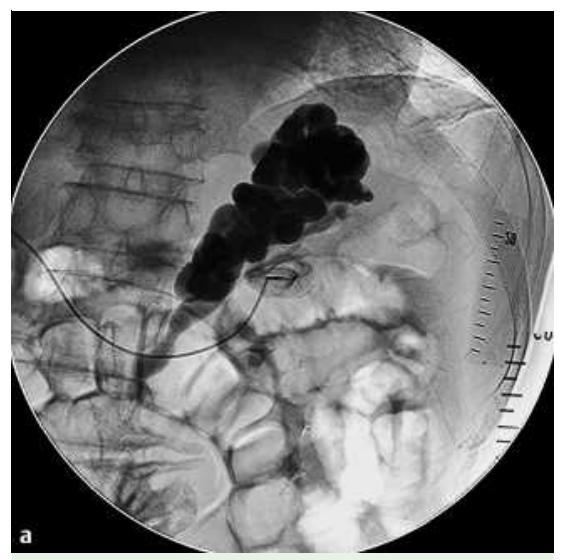

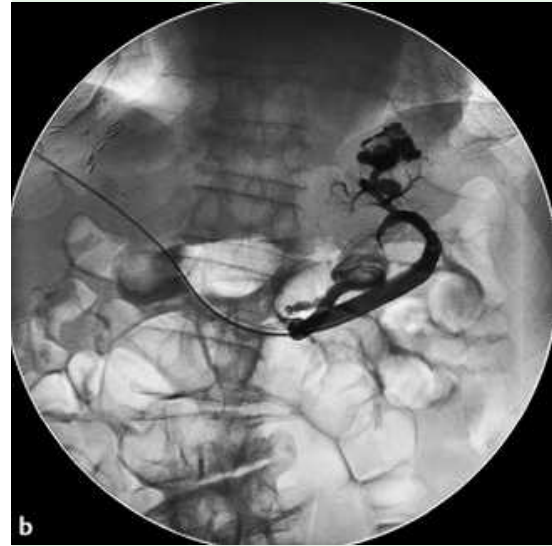

Fig. 2 Percutaneous transhepatic portographic images demonstrated that the gastric varices consisted mainly of a the posterior gastric vein and $\mathbf{b}$ the short gastric vein.

tric vein [4]. An occlusive balloon catheter was inserted through the gastrorenal shunt. The sclerosing agent used for BRTO was slowly infused through the posterior gastric vein in a antegrade manner [2]. In addition, some microcoils were also placed in the posterior gastric vein. Follow-up endoscopic examination after 10 days showed that the microcoil was exposed in the gastric erosion, and contrast-enhanced abdominal computed tomographic images revealed no enhancement of the gastric varices. We therefore concluded that the gastric varices were completely thrombosed ( $\bullet$ Fig. 3). Follow-up endoscopic examination after 2 months showed disappearance of the gastric varices ( $\bullet$ Fig. 4 ).

Although endoscopic treatment options for gastric variceal hemorrhage, such as the injection of cyanoacrylate-based tis-

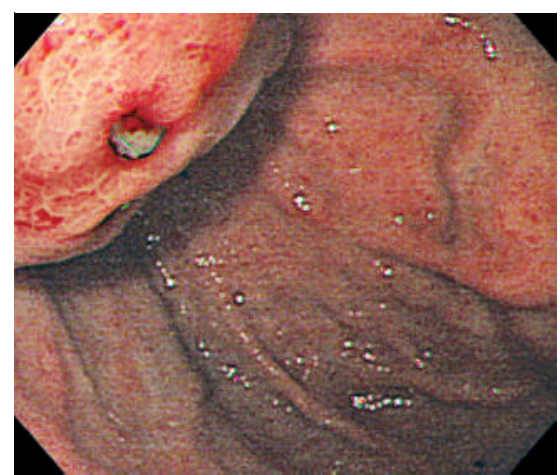

Fig. 3 Endoscopic examination after 10 days revealed exposure of the microcoil.

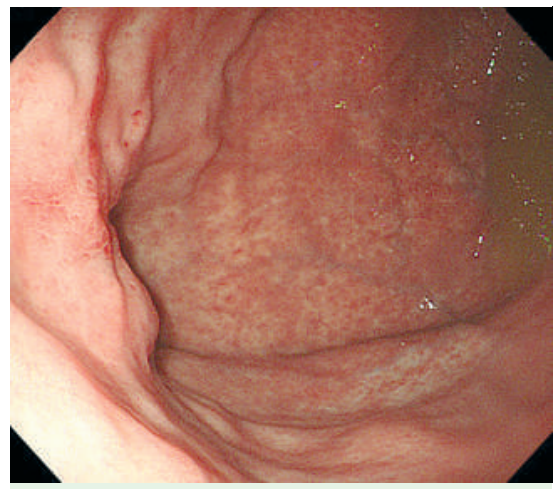

Fig. 4 Endoscopic examination after 2 months showed that the gastric fundal varices had been eradicated.

sue adhesives, alcohol, sclerosants, and the use of band ligation, have been studied, the efficacy or superiority of one therapy over another remains controversial [5]. However, combined BRTO and PTO therapy can obstruct both the feeding and the draining veins of gastric varices, and we suggest that this method can be more effective than the alternatives [2]. In addition, exposure of the microcoil in gastric varices is rare, but is one of the signs of thrombus formation in gastric varices.

Endoscopy_UCTN_Code_CCL_1AB_2AD_3AZ

\section{H. Fukatsu, H. Kawamoto, R. Harada, K. Tsutsumi, M. Fujii, N. Kurihara, T. Ogawa, E. Ishida, Y. Okamoto, H. Okada, K. Sakaguchi}

Department of Gastroenterology and Hepatology, Okayama University Graduate School of Medicine, Dentistry, and Pharmaceutical Sciences, Okayama, Japan

\section{References}

1 Sarin SK, Lahoti D, Saxena SP et al. Prevalence, classification and natural history of gastric varices: a long-term follow-up study in 568 portal hypertension patients. Hepatology 1992; 16: $1343-1349$ 
2 Arai $H$, Abe T, Takagi $H$ et al. Efficacy of balloon-occluded retrograde transvenous obliteration, percutaneous transhepatic obliteration and combined techniques for the management of gastric fundal varices. World J Gastroenterol 2006; 12: 3866 3873

3 Kiyosue H, Mori H, Matsumoto S et al. Transcatheter obliteration of gastric varices. Part 1. Anatomic classification. Radiographics 2003; 23: $911-920$

4 Kiyosue H, Mori H, Matsumoto S et al. Transcatheter obliteration of gastric varices. Part 2. Strategy and techniques based on hemodynamic features. Radiographics 2003; 23: 921-937

5 Qureshi W, Adler DG, Davila $R$ et al. ASGE Guideline: the role of endoscopy in the management of variceal hemorrhage, updated July 2005. Gastrointest Endosc 2005; 62: $651-655$
Bibliography

DOI $10.1055 / \mathrm{s}-2007-966370$

Endoscopy 2007; 39: 247-248

(c) Georg Thieme Verlag KG Stuttgart · New York . ISSN 0013-726X
Corresponding author

\section{H. Kawamoto}

Department of Gastroenterology and Hepatology Okayama University Graduate School of Medicine Dentistry, and Pharmaceutical Sciences

2-5-1 Shikata-cho

Okayama

700-8558

Japan

Fax: +81-86-223-5991

h-kawamo@md.okayama-u.ac.jp 